\title{
Does Curriculum 2005 promote successful learning of elementary algebra?
}

\author{
Nelis Vermeulen \\ Faculty of Education and Social Sciences, Cape Peninsula University of Technology \\ Email: vermeulenc@cput.ac.za
}

\begin{abstract}
This article reviews literature, previous to the development of Curriculum 2005, describing possible causes and solutions for learners' poor performance in algebra. It then analyses the Revised National Curriculum Statement for Mathematics in an attempt to determine whether it addresses these causes and suggested solutions. This analysis finds that the curriculum to a large extent does address them, but that some are either not addressed, or addressed only implicitly. Consequently, Curriculum 2005 may only partly promote successful learning of elementary algebra.
\end{abstract}

\section{Introduction}

For many years now, mathematics educators have been concerned about the quality of learners' knowledge and understanding of elementary algebra. Numerous research projects have been undertaken internationally and a wealth of knowledge regarding learners' understanding and the way in which they learn has been accumulated. Based on these insights and often under the banner of "reform in algebra", researchers have made a number of suggestions to improve the practice of elementary algebra teaching. These not only include suggested approaches in the early high school years, but also essential groundwork to be done in the primary school years.

This article reviews literature previous to the development of Curriculum 2005, which reflects on problems observed and reported on in learners' knowledge and understanding of elementary algebra. It then highlights a few suggested reasons for these and briefly reports on suggestions to improve the practice of elementary algebra teaching. The article then analyses the Learning Outcomes as specified by the Revised National Curriculum Statement for Mathematics (Department of Education, 2002), and evaluates whether these outcomes and associated Assessment Standards correspond with the earlier mentioned suggestions for improving the practice of elementary algebra teaching. The article concludes with a number of recommendations for research and teacher training, based on lessons learnt in the USA with the implementation of the National Council of Teachers of Mathematics (NCTM) Principles and Standards (National Council of Teachers of Mathematics, 2000).

\section{What is elementary algebra?}

If one randomly poses the question, "what is algebra?" to high school learners, the following responses are certain to emerge: algebra is "working with symbols", "finding the unknown", "simplifying", "solving for x". This extremely limited perception of algebra is hardly surprising, since "the traditional image of algebra, based on more than a century of school algebra, is one of simplifying algebraic expressions, solving equations, learning the rules for manipulating symbols" (Kaput, 1999: 133). Asked how they feel about algebra, learners may often provide answers such as "I don't like it, because I don't see why we study it", "Where are we ever going to use it?", "It is boring", "It is so abstract!" and "I am scared of it".

According to the Revised National Curriculum Statement for Mathematics (RNCSM) "Algebra is the language for investigating and communicating most of Mathematics. Algebra can be seen as generalised arithmetic, and can be extended to the study of functions and other relationships between variables" [italics by author] (Department of Education, 2002: 9).

Viewed as generalised arithmetic, algebra essentially refers to the following two key aspects:

- The manipulations in algebra are based on exactly the same principles as those underlying calculations in arithmetic, namely the properties of operation (primarily the distributive and commutative properties).

- Number properties and patterns present in arithmetic can be generalised, and described in symbolic notation.

Bednarz, Kieran and Lee (1996: 3) indicate various "...conceptions (explicit and more often implicit) of algebra: the study of a language and its 
syntax; the study of solving procedures for certain classes of problems, algebra here being conceived of not only as a tool for solving specific problems but also as a tool for expressing general solutions; the study of regularities governing numerical relations, a conception of algebra that centres on generalization and that can be widened by adding components of proof and validation; and the study of relations among quantities that vary" [italics by author].

National Council of Teachers of Mathematics (1994) distinguishes four organising themes or conceptual organisers in algebra, namely:

- Functions and relations: Behind the equations, tables and graphs so common to algebra is the central mathematical concept of function... Functions, and the related concept of variable, give organised ways of thinking about an enormous variety of mathematical settings.

- Modelling: Many complex phenomena can be modelled by relatively simple algebraic relationships...Viewing algebraic relations in terms of the phenomena they model is an effective way of giving life to them and bringing to the study of algebra the richness of experience all students carry with them.

- Structure: Through the efficient and compressed symbol systems of algebra, deep yet simple structures and patterns can be represented.

- Language and representation: Algebra can be seen as a language - with its various 'dialects' of literal symbols, graphs, and tables. For instance, algebra can be seen as the language for generalizing arithmetic [italics by author]. (National Council of Teachers of Mathematics, 1994: 8)

Booth (1986) states: "One of the important functions of algebra is to permit the concise representation of general relationships and procedures. The value of this representation, in turn, is to enable a wide range of problems, to which these relationships or procedures relate, to be more readily solved. It also allows new relationships and procedures to be derived by appropriate manipulation of the old" [italics by author].

In summary, algebra can therefore be described as:

- a mathematical language that enables us to express generalisations, to investigate and describe patterns, relationships and procedures, and to derive new relationships and procedures by appropriate manipulation;
- generalised arithmetic;

- a study of relationships between variables; and

- a tool used to solve problems inside and outside mathematics, often through modelling.

Elementary algebra is that subset of algebra traditionally addressed in grades 7,8 and 9. This entails the conceptualisation, formalisation, manipulation and application of the notions variable, algebraic expression, equation and relationships between variables, namely, the function concept.

\section{Problems experienced in elementary algebra}

Most mathematics teachers are familiar with the following typical errors made by grade 8 and 9 (and even higher) learners:

- Conjoining or closure: $3+x=3 x$ or $x+y=x y$

- Overgeneralisation of the distributive property: $\sqrt{x+y}=\sqrt{x}+\sqrt{y} ;(x+y)^{2}=x^{2}+y^{2}$ or $\sin (x+y)=\sin x+\sin y$

- Incomplete application of the distributive property: $2(x+y)=2 x+y$ or

$$
\frac{4 x+6}{2}=2 x+6
$$

Most mathematics teachers have also observed the tendency by their learners to change an algebraic expression into an equation, as illustrated by an excerpt from an interview with a first year mathematics education student (Vermeulen, 2000); $\mathrm{I}=$ interviewer and $\mathrm{S}=$ student.

I: If I write there $3 x+5$, what does it mean to you?

$\mathrm{S}: \ldots$ you need to find $\mathrm{x} \ldots$ you need to say $3 x+5$ is equal to zero.

I: Hmmm...

S: Then you take the 5 to the other side and ...

Numerous reports of learners' lack of understanding and misconceptions are to be found in literature, of which only a few are highlighted below.

As part of the extensive CSMS (Concepts in Secondary Mathematics and Science) research programme, Küchemann (1981: 102) investigated close to 1,000 14-year-olds' understanding of letter symbols in algebra. He concluded that children interpret letter symbols in the following ways, arranged here in a hierarchical way with number 6 the most appropriate interpretation of letter symbols:

1) Letter evaluated: This is when a person assigns a numerical value to the letter symbol from the outset. This is done to avoid working with the 
letter. Example: replacing $a$ by 1 and $b$ by 2, presumably because $a$ and $b$ are the first and second letters of the alphabet.

2) Letter not used: The letter is simply ignored. Example: In response to the question: "If $e+f=$ 8 , then $e+f+g=\ldots$ ", $34 \%$ of the respondents gave the answers 12,9 or 15 , rather than the correct $8+g$, thereby effectively ignoring the letter symbol $g$.

3) Letter used as an object: The letter is regarded as shorthand for an object or an object in its own right. Example: the familiar $2 \mathrm{a}+3 \mathrm{~b}$ interpreted as 2 apples and 3 bananas, or as 2 a's and 3 b's. Other researchers refer to this phenomenon as "using letter symbols as labels". A familiar example is the "studentprofessor' problem: "Write an equation using the variables $S$ and $P$ to represent the following statement: 'There are six times as many students as professors at this university'. Use $S$ for the number of students and $\mathrm{P}$ for the number of professors." A surprising number of people give the following equation: $6 \mathrm{~S}=\mathrm{P}$, and explains it as 'six students for every one professor', which is similar to the comparison $10 \mathrm{~mm}=1 \mathrm{~cm}$. (Clement, Lockhead \& Monk, 1981, as cited by Kinzel, 1999: 436).

4) Letter used as a specific unknown: The letter symbol is regarded as a specific but unknown number.

5) Letter used as a generalised number: The letter symbol is seen as representing several values rather than just one.

6) Letter used as a variable: The letter symbol is seen as representing a range of unspecified values, and a systematic relationship is seen to exist between two such sets of values.

The single cases indicated above are the results of learners' lack of understanding of the meaning of the basic concepts in elementary algebra, namely, variables, algebraic expressions and equations, the purpose and underlying principles of simplification or manipulation of algebraic expressions, as well the notion of algebra as a language. Numerous examples can also be quoted on learners' lack of understanding of the function concept.

\section{Causes and solutions}

Numerous causes for children's lack of understanding of concepts in elementary algebra have been suggested by researchers and educators, usually accompanied by suggested solutions. I focus on three categories, namely similarities and differences between arithmetic and algebra, unhelpful teaching, and learning difficulties.

\section{Similarities and differences between arithmetic and algebra}

Booth (1988), reporting on the Strategies and Errors in Secondary Mathematics (SESM) research project conducted in the United Kingdom between 1980 and 1983, provides a useful framework for the classification and investigation of children's errors in elementary algebra. During the same period, as well as subsequent to the SESM project, many other researchers arrived at similar conclusions. According to Booth, many errors made by children could be traced to their ideas of aspects such as those described in the four sections below.

\section{The focus of algebraic activity and the nature of answers}

In arithmetic, the focus of activity traditionally is on finding particular numerical answers. In algebra, however, the aim of manipulation is not so much the finding of an "answer" in simplified form, as the replacement of one algebraic expression by another more useful, yet still equivalent, expression. "More useful" is a function of the task or activity, for example, to evaluate the expression $2 x(7 x+5)-14 x^{2}$ for any value of $x$ would be easier if the expression is first replaced by the simpler, yet equivalent, expression $10 x$. On the other hand, to solve the equation $x^{2}-3 x+2=0$, a more useful form of the expression on the left side would be $(x-1)(x-2)$.

Operating in an arithmetic conceptual framework may be the reason why children are unwilling or unable to view $2 n$ as a proper answer to the question: "What is the perimeter of a shape with $n$ sides of which each is of length 2?" This framework may also be the cause of conjoining as in $x+y=x y$ where children have a cognitive difficulty in accepting lack of closure.

Booth suggests another aspect of this problem: "Not only are unclosed algebraic expressions legitimate as 'answers', but the expression represents both the procedure as well as the answer itself. For example, ' $n+3$ ' can be both an 'instruction' (or procedure) statement, which states that 3 is to be added to the variable $n$, and an 'answer', which gives the result of having performed the addition." (Booth, 1988: 24). This problematic situation was termed by Matz (1979) a "process-product dilemma" and later by Sfard (1991) a "process-object duality". 


\section{Nelis Vermeulen}

\section{Notation and convention in algebra}

Part of the problem in children's attempts to simplify expressions such as $2 a+5 b$ concerns their interpretation of the operation symbol. In arithmetic, symbols such as + and $=$ are typically interpreted in terms of actions to be performed, so that for children + means to actually perform the operation (addition) and = means to write down the answer. In algebra, however, the $=$ sign is not the signifier of the 'answer' in the same sense as in arithmetic, but rather serves as an equivalence indicator. For example, the $=\operatorname{sign}$ in $(x-1)(x-2)$ $=x^{2}-3 x+2$ simply indicates that these two expressions are equivalent. The same applies to $x^{2}-3 x+2=(x-1)(x-2)$.

Concatenation, that is, the juxtaposition of two symbols, is another source of error. In arithmetic, concatenation such as 32 implicitly denotes addition (by convention, 32 means $30+2$ ), while in algebra concatenation such as $x y$ by convention denotes multiplication.

\section{Letters and variables}

Although the most obvious difference between arithmetic and algebra is the use of letters in algebra, letters also appear in arithmetic, but in quite a different way, and with a completely different purpose. The letters ' $\mathrm{m}$ ' and ' $c$ ' for instance, may be used in arithmetic to represent 'metres' and 'cents', rather than representing the number of metres or the number of cents, as in algebra. To further compound this problem, letters in algebra do sometimes serve as 'labels' rather than representing a (range of) unknown value(s). For example, all of us have written the area formula for a rectangle as $a=l \times b$, where $a$ indicates the area, $l$ the length and $b$ the width. Even worse is the formula for the perimeter of a rectangle, when written as $p=2 l+2 b$.

One of the most important aspects of algebra is the notion of 'variable'. Even when children do interpret letters as representing numbers, there is a strong tendency for the letter to be regarded as standing for specific or unique numbers, as noted earlier in this article (Küchemann, 1981). This may well be a construct formed in children's arithmetic conceptual framework, since in arithmetic, symbols representing quantities always do signify unique values. For example, the symbol ' 3 ' represents only and exactly three. A related, but inverse, problem arising from this perception is that children often assume that different letters must represent different numerical values. For example, although they may accept that $x$ and $y$ in $x+y$ can assume any value, they find it hard to accept that $x$ and $y$ can assume the same value.

\section{Learners' understanding of arithmetic}

Most of the difficulties so far have been discussed from the perspective of the differences between arithmetic and algebra. However, algebra is not separate from arithmetic; indeed, in many respects algebra is generalised arithmetic. But to appreciate the generalisation of arithmetical relationships and procedures children must first be(come) explicitly aware of those relationships and procedures in the arithmetical context. In this case, the difficulties that children experience in elementary algebra are not so much difficulties in algebra itself as problems in arithmetic that remain unresolved.

In reform arithmetic classrooms learners are allowed to use their own, informal computational methods, initially based on their theorems-inaction (Vergnaud, 1989). The danger for algebra in this practice is as severe as in the traditional method of teaching computational procedures via the standard algorithms, since learners may never become explicitly aware of the underlying structures of these computational procedures. And these structures are exactly the same as those underlying manipulation in algebra, namely, the properties of operation, for example, the commutative and distributive property. To illustrate this, consider the following two cases.

In a reform classroom a learner may calculate $32 \times 6$ in a number of ways; it may be very implicit, in that the child may not necessarily present it as shown here.

$32 \times 6$

$=6 \times 32$ [uses the commutative property for multiplication]

$=6 \times(30+2)[$ decomposes 32 ; some learners even as $10+10+10+2]$

$=(6 \times 30)+(6 \times 2)$ [uses the

$=180+12$

$=192$

In a traditional classroom the same calculation may be carried out as follows, using the standard algorithm for long multiplication; the learner's reasoning appears in square brackets after each step.

$$
\begin{aligned}
& \begin{array}{r}
32 \\
\times \frac{6}{12}
\end{array}[6 \times 2=12] \\
& \underline{18}[6 \times 3=18 ; \text { and move the digit one } \\
& \text { place to the left }] \\
& 192[2+0 \text { is } 2 ; 1+8 \text { is } 9 ; 0+1=1]
\end{aligned}
$$


In this procedure 32 was decomposed as $30+2$, and 6 was multiplied with both 2 and 30 (and not 3 ). Therefore, the distributive property was most certainly used; only, this standard procedure is so deceptively simple that a primary school learner will never realise it - unless s/he is made explicitly aware of it. And so for the learner in the reform classroom - her/his intuitive use of these properties must be gradually explicated and generalised.

In algebra, these properties of operation are of crucial importance - they are exactly the principles that govern equivalence. Their correct application ensures the creation of equivalent algebraic expressions. It is for this reason that a number of researchers have indicated the importance of structure. Kieran (1989), amongst others, emphasises that an important part of learners' problems in elementary algebra is their difficulty to recognise and use structure. Kieran sees algebra as the formulation and manipulation of general statements about numbers, and hence hypothesises that children's prior experience with the structure of numerical expressions in primary school should have an important effect on their ability to make sense of algebra. Booth (1989) expresses the same view:

...a major part of students' difficulty in algebra stems precisely from their lack of understanding of arithmetical relations. The ability to work meaningfully in algebra, and thereby handle the notational conventions with ease, requires that students first develop a semantic understanding of arithmetic. (1989: 58)

Kieran (1989) states that much of school arithmetic is orientated towards "finding the answer". This emphasis allows children to get by with informal, intuitive procedures. However, in algebra, they are required to recognise and use the structure that they have been able to avoid in arithmetic.

From the above the conclusion can be drawn that structure should be a unifying concept in arithmetic and algebra. This implies that primary school learners should be given opportunities to become explicitly aware of:

- the structure of numerical calculations, based on the properties of operation, as well as

- the notion of equivalence,

Furthermore, this explicit awareness should be gradually generalised (in words and in symbolic language) to facilitate a natural transition to the use of letter symbols and the manipulation of symbolic (algebraic) expressions.

\section{Unhelpful teaching}

Orton and Frobisher (1996) identify two major categories of causes of learners' lack of understanding and errors in elementary algebra, namely, "unhelpful teaching and learning difficulties". "Unhelpful teaching" practices usually stem from the traditional approach to teaching elementary algebra, where the emphasis is on manipulation. For example, learners do not get the opportunity to understand algebra in its fullest context, as generalised arithmetic, since little attempt is made by the teacher to encourage conceptual links between arithmetic and algebra.

Another "unhelpful teaching" strategy is the way in which teachers introduce letter symbols and motivate manipulation with letter symbols and expressions containing them. A well-known strategy is the "fruit salad" approach where learners are taught that " $3 a+4 a$ equals $7 a$, because 3 apples plus 4 apples equals 7 apples. However, $3 a+4 b$ cannot be simplified, because you cannot add 3 apples and 4 bananas - unless you want to say that it equals 7 fruit". This perception of the meaning of letter symbols corresponds to what Küchemann (1981) termed as 'letters as objects' or using the letter symbol as a label. This wrong perception of letter symbols created within learners is compounded by the use of initial letters of variable quantities, for example, $h$ for the height, $d$ for the distance, $t$ for time, etc.

The traditional approach to teaching elementary algebra supplies learners with the notation but does not attend to developing appropriate mental referents for the notation (Kinzel, 1999: 440). To overcome this, teachers should assist learners to develop the concept of variables/-ility. This may be achieved by describing patterns and relationships in ever increasing formal language (from words to letter symbols), as well as exploring a range of input values for letter symbols in algebraic formulas or expressions.

\section{Learning difficulties}

Whereas Orton and Frobisher (1996) refer to "learning difficulties", Herscovics (1989) refers to "cognitive obstacles". He states that the acquisition of new conceptual knowledge (schemata) by the learner "is strewn with cognitive obstacles", and that cognitive obstacles should be considered normal and inherent to the learner's construction of knowledge. From the Piagetian perspective, acquisition of knowledge involves both assimilation (the integration of new knowledge into the existing cognitive structure) and accommodation (changes in the learner's cognitive 
structure necessitated by the acquisition of new knowledge). However, accommodation does not occur easily as existing cognitive structures are difficult to change significantly - their very existence becoming cognitive obstacles in the construction of new knowledge. Several researchers, including Collis (1974, as cited by Herscovics, 1989: 62) have found that learners' prior arithmetical experience can be a source of difficulty in their construction of meaning in algebra.

Therefore, arithmetic teaching and learning should encourage learners to construct algebraic cognitive structures right from their early primary school years. Of course, initially these structures will be very simple. However, they need to be developed and expanded until the learner is introduced to algebra in the high school so that consequent learning of algebra is a process of assimilation rather than accommodation. As such, one would then speak of a natural progression from arithmetic to algebra, rather than a transition, as is currently the case.

\section{Requirements of an algebra curriculum}

Reflecting upon the research-based findings and suggestions in the previous section, it would appear that in order to promote successful learning of elementary algebra, the curriculum should incorporate a number of aspects. These are introduced in the sections below.

\section{Aspect 1. Enable learners to experience and appreciate algebra as generalised arithmetic}

The algebra curriculum should enable learners to experience and appreciate algebra as generalised arithmetic. In order to do this, it should promote the following:

1.1 Learners must become explicitly aware of structure, primarily that,

1.1.1 the same principles (namely, the properties of operation) underlie computation in arithmetic and manipulation in algebra;

1.1.2 equivalence of expressions, whether numerical or algebraic, is preserved by the correct application of properties of operation, and that manipulation in algebra merely transforms expressions into more useful equivalent (and often simpler) expressions;

1.1.3 there are therefore structural similarities, but also differences, between arithmetic and algebra, and what these similarities and differences are.

1.2 learners must experience and appreciate algebra as a language used to express generalisation of patterns and procedures, thoroughly understanding the semantics and syntax of this language, including proper understanding of the meaning and function of letter symbols, algebraic expressions and equations, and manipulations performed upon them.

\section{Aspect 2. Enable learners to use and appreciate algebra as a means to describe relationships between variables}

The algebra curriculum should enable learners to use and appreciate algebra as a means to describe relationships between quantities that vary variables - inside and outside mathematics. Specific reference should be made to the following:

2.1 constructing meaning for the concept of variables/-ility;

2.2 appreciating that a relationship exists between different values of the unknown/ variable/letter symbol and the resulting values of the algebraic expression;

2.3 demonstrating the relationship between variables in several ways: verbally, using flow diagrams, tables, algebraic expressions/ formulas and graphs;

2.4 substitution into algebraic expressions and solving equations as two (inverse) processes utilised to determine values for the two variables - substitution to determine output values, and solving equations to determine input values.

\section{Aspect 3. Enable learners to use and appreciate algebra as a tool to solve problems}

The algebra curriculum should enable learners to use and appreciate algebra as a tool to solve problems, inside and outside mathematics, often through a modelling process.

\section{A spiral learning process beginning in primary school}

It is important to realise that the various categories and subcategories above cannot be separated in practice. They overlap extensively, supporting and reinforcing, informing and complementing one another. Elementary algebra can therefore not be taught in a simple linear fashion, as was often the case with the traditional approach (letter symbols 
$\rightarrow$ algebraic expressions $\rightarrow$ solution of equations $\rightarrow$ functions and graphs). In fact, a curriculum designed to satisfy the three aspects above must commence in the early primary school years and follow a spiral approach, where these aspects are addressed in a variety of contexts while continuously generalising and formalising.

\section{Curriculum 2005}

The Revised National Curriculum Statement (RNCS) (Department of Education, 2002) can be viewed as the third attempt to formulate South Africa's outcomes-based curriculum for school grades R-9 - the Foundation, Intermediate and Senior phases or General Education and Training (GET). This is referred to as Curriculum 2005. As was the case with the Draft National Curriculum Statement, the RNCS for Mathematics is a muchsimplified version of the original curriculum documents, and contains only five Learning Outcomes (LOs), as opposed to ten in the original version. These LOs are:

LO 1: Numbers, operations and relationships

LO 2: Patterns, functions and algebra

LO 3: Space and shape (Geometry)

LO 4: Measurement

LO 5: Data handling

Each LO is supplemented by a Learning Outcome Focus and a Phase Focus for each of the three phases in GET (Foundation, Intermediate and Senior). Assessment Standards are provided for each grade against which learners' attainment of the LOs are to be assessed.

Of particular interest for the purpose of this article are LOs 1 and 2. As stated earlier, the aspects to be addressed by the algebra curriculum detailed above - should take place in a variety of contexts, including LOs 3, 4 and 5, where appropriate. However, the core of the development of learners' knowledge and understanding of algebra will, by the very nature of algebra, take place within the first two LOs.

In an attempt to evaluate how well this curriculum reflects perspectives towards the teaching and learning of algebra, as expressed in the three aspects on page 7, we proceed as follows:

- Relevant sections from the Learning Outcome Focus of each of LOs 1 and 2 will be quoted from Department of Education (2002), followed by the focus of each LO in each of the phases (Foundation, Intermediate and Senior). Excerpted statements that address aspects 1 to 3 will be italicised and numbered by a superscript number, and these statements will form the core of the comparison between the curriculum and the requirements formulated as aspects 1 to 3 .

- In tabular form, the following will be listed:

- Each of aspects 1 to 3, and their subaspects. (Note: only the numbers of the relevant sub-aspects will be indicated in the tables, for example, 1.1.1, 1.1.2, etc).

- Relevant excerpted and numbered statements from the LO Focus or Phase Focus. (Note: only the superscripted numbers of the particular excerpted statements will be indicated in the tables, e.g. ${ }^{1},{ }^{2}$, etc).

- Relevant Assessment Standards. (Note: only the numbers of the relevant Assessment Standards will be indicated in the tables. The list of Assessment Standards and their corresponding numbers appear in the text adjacent to the relevant table).

- Comments and verdicts indicating the degree to which the curriculum satisfies aspects 1 to 3 will be supplied.

This will be done alternately for LO1 and LO2.

\section{Learning Outcome 1: Number, Operations and Relationships}

The learner will be able to recognise, describe and represent numbers and their relationships, and to count, estimate, calculate and check with competence and confidence in solving problems.

\section{Learning Outcome Focus}

Learning Outcome 1 builds the learner's number sense, which is the foundation of further study in Mathematics. It also develops the learner's understanding of:

- what different kinds of numbers mean;

- how different kinds of numbers relate to each other;

- the relative size of different numbers;

- how different numbers can be thought about and represented in different ways; and

- the effect of operating with numbers. ${ }^{I}$

Essential to the development of number sense is knowledge of basic number facts, the use of efficient and accurate methods for calculation ${ }^{2}$ and measurement, and a range of strategies for estimating and checking results. 


\section{Foundation Phase Focus}

In this phase, the number concept of the learner is developed through working with physical objects in order to count collections of objects, partition and combine quantities, skip count ${ }^{3}$ in various ways, solve contextual (word) problems, and build up and break down numbers. ${ }^{4}$

\section{Intermediate Phase Focus}

Through a study of a variety of number patterns, the learner should recognise and describe properties of numbers, including identity properties, factors and multiples, and properties of operations, including commutative, associative and distributive properties. ${ }^{5}$ The purpose should be for the learner to recognise:

- what the properties are; and

- how they can be used to solve problems and simplify calculations. ${ }^{6}$

\section{Senior Phase Focus}

The learner should be encouraged to:

- sharpen the ability to estimate and judge the reasonableness of solutions, using a variety of strategies; and

- use number knowledge to develop algebraic skills. $^{7}$

\section{Learning Outcome 2: Patterns, functions and algebra}

The learner will be able to recognise, describe and represent patterns and relationships, as well as to solve problems using algebraic language and skills.

\section{Learning Outcome Focus}

Algebra is the language for investigating and communicating most of Mathematics. Algebra can be seen as generalized arithmetic, and can be extended to the study of functions and other relationships between variables. A central part of this outcome is for learners to achieve efficient manipulative skills in the use of algebra. Learning Outcome 2 focuses on:

- Describing patterns and relationships ${ }^{8}$ through the use of symbolic expressions, graphs and tables. ${ }^{9}$

- Identifying and analysing regularities and changes in patterns and relationships that enable learners to make predictions and solve problems.

Mathematical skills are developed over time.

The learner should be given opportunities at every grade level to develop these skills to greater levels of sophistication. ${ }^{10}$
Contexts should be selected in which the learner can use algebraic language and skills to describe patterns and relationships ${ }^{11}$ in a way that builds awareness of other Learning Areas, as well as human rights, social, economic, cultural, political and environmental issues.

\section{Foundation Phase Focus}

In this phase, the focus of this outcome is to lay the foundation for developing algebra in the Intermediate and Senior Phases. ${ }^{12}$ This foundation can be established by helping the learner to use physical objects and drawings to copy, extend, create and describe:

- Geometric patterns ${ }^{13}$ (e.g. pictures), and

- Numeric patterns (e.g. skip counting). ${ }^{14}$

\section{Intermediate Phase Focus}

In the Intermediate Phase, the study of numeric and geometric patterns is extended with a special focus on the relationships:

- Between terms in a sequence; and.

- Between the number of the term (its place in the sequence) and the term itself. ${ }^{15}$

This study of numeric and geometric patterns develops the concepts of variables, relationship and function. The understanding of these relationships by the learner will allow her or him to describe the rules generating the patterns. ${ }^{16}$

This phase has a particular focus on the use of different, yet equivalent, representations of problems and relationships - in other words: words, flow diagrams, tables and simple graphs. ${ }^{17}$ Graphs are not dealt with in this Learning Outcome in the Intermediate Phase. However, the learner is given opportunities to read, interpret and draw graphs within data contexts (see Learning Outcome $5)$.

\section{Senior Phase Focus}

In the Senior Phase, the focus of Patterns, Function and Algebra is to formalise the rules generating patterns. ${ }^{18}$ Learners should continue to:

- Investigate numerical and geometric patterns to establish the relationship between variables, ${ }^{19}$ and

- Express rules governing patterns in algebraic language or symbols. ${ }^{20}$

The learner continues to analyse situations in a variety of contexts $^{21}$ in order to make sense of them, with added ability to represent and describe them in algebraic language, formulae, expressions and graphs. ${ }^{22}$ The learner should be exposed to a variety of functions and graphs to compare their 
global features, rather than to focus on the behaviour or features of particular functions or graphs. $^{23}$

The learners should also study properties of algebraic expressions by manipulating them with sufficient practice to form simpler equivalent expressions $^{24}$ for calculating and solving problems. $^{25}$ The learners should develop an appreciation of how algebraic manipulation is useful for solving problems (and not engage in algebraic manipulation for its own sake). ${ }^{26}$

We now turn to each of the aspects 1 to 3 and their subsections individually, and compare them with the LO Foci, Phase Foci and Assessment Standards to determine which of these aspects are addressed by the curriculum, and to what extent, and which are excluded or not explicitly addressed.

\section{Assessment Standards used in Tables 1 to 12}

The assessment standards used for each table (Tables 1 to 12) are identified below. These appear adjacent to, or on the previous page from, the relevant table.

\begin{tabular}{|c|c|c|c|c|c|c|}
\hline & \multicolumn{5}{|c|}{ Where/how addressed in curriculum } & \multirow[t]{2}{*}{ Comments and verdict regarding 1.1.1 } \\
\hline \multirow[t]{8}{*}{1.1 .1} & LO & Phase(s) & $\begin{array}{l}\text { Numbered } \\
\text { statements }\end{array}$ & $\begin{array}{c}\text { Assessment } \\
\text { Standard }\end{array}$ & Grade(s) & \\
\hline & \multirow[t]{7}{*}{1} & $F, I, S$ & $\begin{array}{l}1 \\
2\end{array}$ & & $\begin{array}{l}\text { All } \\
\text { grades in } \\
\text { GET }\end{array}$ & $\begin{array}{l}\text { Comment: Statements }{ }^{1} \text { and }{ }^{2} \text { from the } \\
\text { LO Focus are of a general nature, and } \\
\text { are addressed in more detail in the rest } \\
\text { of this table. }\end{array}$ \\
\hline & & \multirow[t]{2}{*}{$\mathrm{F}$} & \multirow[t]{2}{*}{4} & $1 \mathrm{~A}$ & $\mathrm{R}$ & \multirow{2}{*}{$\begin{array}{l}\text { Comment: Building up and breaking } \\
\text { down numbers pave the way towards } \\
\text { using the distributive property, and } \\
\text { should therefore be included in the } \\
\text { curriculum (which it is). } \\
\text { Verdict: Adequately addressed. }\end{array}$} \\
\hline & & & & 1B & $1 ; 2 ; 3$ & \\
\hline & & \multirow[t]{2}{*}{$\mathrm{I}$} & \multirow{2}{*}{$\begin{array}{l}5 \\
6\end{array}$} & $1 \mathrm{C}$ & $4 ; 5 ; 6$ & \multirow[b]{2}{*}{$\begin{array}{l}\text { Comment: Properties of operations are } \\
\text { explicitly addressed. However, teachers } \\
\text { should note that all the Assessment } \\
\text { Standards mentioned in the corres- } \\
\text { ponding Assessment Standards column } \\
\text { contribute towards developing and } \\
\text { applying them, and even though their } \\
\text { names need not be known, recognition, } \\
\text { description and using them should be } \\
\text { emphasised in class. Teachers in reform } \\
\text { classes should also be aware of the } \\
\text { Model describing levels of awareness of } \\
\text { these properties (Vermeulen 1995: } 421- \\
422 \text { ). } \\
\text { Verdict: Adequately addressed. }\end{array}$} \\
\hline & & & & $1 \mathrm{D}$ & 6 & \\
\hline & & S & 7 & $1 \mathrm{E}$ & $7 ; 8$ & $\begin{array}{l}\text { Comment: The curriculum apparently } \\
\text { encourages learners to investigate } \\
\text { different calculating techniques, thereby } \\
\text { evaluating explicit use of the properties } \\
\text { of operation. This should further } \\
\text { explicate learners' knowledge and } \\
\text { understanding. } \\
\text { Verdict: Adequately addressed. }\end{array}$ \\
\hline & & \multicolumn{5}{|c|}{$\begin{array}{l}\text { Final verdict: } 1.1 .1 \text { is adequately addressed in LO1, sometimes explicitly, but often implicitly. } \\
\text { Teachers need to be aware of Assessment Standards that implicitly contribute towards } \\
\text { realising } 1.1 .1 \text {, as mentioned above. }\end{array}$} \\
\hline
\end{tabular}

Table 1. Aspect 1: enable learners to experience and appreciate algebra as generalised arithmetic (LO1). 
Table 1 Assessment Standards

1A: Building up and breaking down numbers to at least 10

1B: Perform calculations ... uses the following techniques ... building up and breaking down numbers

1C:

- Calculates by selecting and using operations appropriate to solving problems that involve:

- addition and subtraction of whole numbers

- multiplication of at least $2 / 3 / 4$ digit by $2 / 3$ digit numbers

- division of at least whole $2 / 3 / 4$ digit numbers by $2 / 3$ digit numbers

- Uses a range of techniques to perform calculations, including building up and breaking down numbers

- Recognises, describes and uses the commutative, associative and distributive properties (the expectation is that learners should be able to use these properties and not necessarily know the names of the properties)

1D: Multiple operations on whole numbers with or without brackets
1E:

- Uses a range of techniques to perform calculations, including the commutative, associative and distributive properties

- Recognises, describes and uses the commutative, associative and distributive properties (the expectation is that learners should be able to use these properties and not necessarily know the names of the properties).

\section{Table 2 Assessment Standards}

2A: Uses conventions of algebraic notation and the commutative, associative and distributive laws to:

- collect like terms

- multiply or divide an algebraic expression

- simplify algebraic expressions given in bracket notation

2B: Uses the distributive law and manipulative skills developed in grade 8 to:

- find the product of two binomials

- factorise algebraic expressions

\begin{tabular}{|c|c|c|c|c|c|c|}
\hline & \multicolumn{5}{|c|}{ Where/how addressed in curriculum } & \multirow[t]{2}{*}{ Comments and verdict regarding 1.1.1 } \\
\hline \multirow[t]{5}{*}{1.1 .1} & LO & Phase(s) & $\begin{array}{l}\text { Numbered } \\
\text { statements }\end{array}$ & $\begin{array}{c}\text { Assessment } \\
\text { Standard }\end{array}$ & Grade(s) & \\
\hline & \multirow[t]{4}{*}{2} & $\mathrm{~F}, \mathrm{I}, \mathrm{S}$ & 10 & & $\begin{array}{c}\text { All } \\
\text { grades in } \\
\text { GET }\end{array}$ & $\begin{array}{l}\text { Comment: The recognition, description and } \\
\text { use of the properties of operation in an } \\
\text { ever-increasing level of sophistication and } \\
\text { generalisation in arithmetic progress } \\
\text { naturally, logically and coherently into their } \\
\text { recognition, description and use in algebra. }\end{array}$ \\
\hline & & \multirow[t]{2}{*}{ S } & \multirow{2}{*}{$\begin{array}{l}24 \\
25 \\
26\end{array}$} & $2 \mathrm{~A}$ & 8 & \multirow[b]{2}{*}{$\begin{array}{l}\text { Comment: Using the properties of } \\
\text { operation to manipulate algebraic } \\
\text { expressions should be a natural } \\
\text { progression from using them for } \\
\text { calculations in arithmetic. However, the } \\
\text { curriculum does not explicitly indicate this } \\
\text { natural, but vital, link. } \\
\text { Verdict: } 1.1 .1 \text { is inadequately addressed. }\end{array}$} \\
\hline & & & & $2 \mathrm{~B}$ & 9 & \\
\hline & & \multicolumn{5}{|c|}{$\begin{array}{l}\text { Final verdict: } 1.1 .1 \text { is inadequately addressed in LO2. Teachers need to be aware of the } \\
\text { importance of } 1.1 .1 \text { and must: } \\
\text { - treat manipulation in algebra as a natural progression from calculation in arithmetic } \\
\text { emphasise the fact that the properties of operation underlie calculation in arithmetic and } \\
\text { manipulation in algebra }\end{array}$} \\
\hline
\end{tabular}

Table 2. Aspect 1 (cont.): enable learners to experience and appreciate algebra as generalised arithmetic (LO2). 


\begin{tabular}{|c|c|c|c|c|c|c|}
\hline & \multicolumn{5}{|c|}{ Where/how addressed in curriculum } & \multirow[t]{2}{*}{ Comments and verdict regarding $\mathbf{1 . 1 . 2}$} \\
\hline \multirow[t]{7}{*}{1.1 .2} & LO & Phase(s) & $\begin{array}{l}\text { Numbered } \\
\text { statements }\end{array}$ & $\begin{array}{l}\text { Assessment } \\
\text { Standard }\end{array}$ & Grade(s) & \\
\hline & \multirow[t]{6}{*}{1} & $F, I, S$ & $\begin{array}{l}1 \\
2\end{array}$ & & $\begin{array}{l}\text { All } \\
\text { grades in } \\
\text { GET }\end{array}$ & $\begin{array}{l}\text { Comment: Statements }{ }^{1} \text { and }{ }^{2} \text { from the LO } \\
\text { Focus are of a general nature, and are } \\
\text { addressed in more detail in the rest of this } \\
\text { table. }\end{array}$ \\
\hline & & $\mathrm{F}$ & & & & $\begin{array}{l}\text { Comment: Equivalence need not be } \\
\text { addressed explicitly at this level. However, } \\
\text { where the opportunity arises, teachers } \\
\text { should introduce it informally. }\end{array}$ \\
\hline & & $\mathrm{I}$ & 5 & $3 \mathrm{~A}$ & $4 ; 5 ; 6$ & Verdict: Addressed, but very implicitly. Not \\
\hline & & & 6 & 3B & 6 & $\begin{array}{l}\text { indicating to teachers that using properties } \\
\text { of operations creates a new, though still } \\
\text { equivalent (different in appearance, but } \\
\text { equal in value) numerical expression. }\end{array}$ \\
\hline & & $\mathrm{S}$ & 7 & $3 \mathrm{C}$ & $7 ; 8$ & $\begin{array}{l}\text { Verdict: Addressed, but very implicitly. Not } \\
\text { indicating to teachers that using properties } \\
\text { of operations creates a new, though still } \\
\text { equivalent (different in appearance, but } \\
\text { equal in value) numerical expression. }\end{array}$ \\
\hline & & \multicolumn{5}{|c|}{$\begin{array}{l}\text { Final verdict: } 1.1 .2 \text { is very implicitly addressed in LO1. Teachers need to be aware of the } \\
\text { notion of equivalence, and that using properties of operations conserve equivalence. } \\
\text { Unfortunately, it is addressed no better in LO2. }\end{array}$} \\
\hline
\end{tabular}

Table 3. Aspect 1 (cont.): enable learners to experience and appreciate algebra as generalised arithmetic (LO1).

3A:

\section{Table 3 Assessment Standards}

- Calculates by selecting and using operations appropriate to solving problems that involve:

- addition and subtraction of whole numbers

- multiplication of at least $2 / 3 / 4$ digit by $2 / 3$ digit numbers

- division of at least whole 2/3/4 digit numbers by $2 / 3$ digit numbers

- Uses a range of techniques to perform calculations, including building up and breaking down numbers

- Recognises, describes and uses the commutative, associative and distributive properties (the expectation is that learners should be able to use these properties and not necessarily know the names of the properties)
3B: Multiple operations on whole numbers with or without brackets

3C:

- Uses a range of techniques to perform calculations, including the commutative, associative and distributive properties

- Recognises, describes and uses the commutative, associative and distributive properties (the expectation is that learners should be able to use these properties and not necessarily know the names of the properties) 


\begin{tabular}{|c|c|c|c|c|c|c|}
\hline & \multicolumn{5}{|c|}{ Where/how addressed in curriculum } & \multirow[t]{2}{*}{ Comments and verdict regarding 1.1.2 } \\
\hline \multirow[t]{5}{*}{1.1 .2} & LO & Phase(s) & $\begin{array}{l}\text { Numbered } \\
\text { statements }\end{array}$ & $\begin{array}{l}\text { Assessment } \\
\text { Standard }\end{array}$ & Grade(s) & \\
\hline & \multirow[t]{4}{*}{2} & $F, I, S$ & 10 & & $\begin{array}{c}\text { All } \\
\text { grades in } \\
\text { GET }\end{array}$ & $\begin{array}{l}\text { Comment: The realisation that using the } \\
\text { properties of operations leads to equivalent } \\
\text { numerical expressions should, through } \\
\text { ever-increasing explication and general- } \\
\text { isation, naturally lead to the same } \\
\text { realisation during algebraic manipulation. }\end{array}$ \\
\hline & & \multirow[t]{2}{*}{ S } & \multirow[t]{2}{*}{$\begin{array}{l}24 \\
25 \\
26\end{array}$} & $4 \mathrm{~A}$ & 8 & \multirow[b]{2}{*}{$\begin{array}{l}\text { Comment: The Phase Focus does mention } \\
\text { equivalence, but this concept is not } \\
\text { reflected in the Assessment Standards. } \\
\text { Verdict: Equivalence is not addressed } \\
\text { sufficiently. Teachers need to know that } \\
\text { properties of operations preserve } \\
\text { equivalence. } \\
\text { Comment: The Phase Focus indicates that } \\
\text { "algebraic manipulation is useful for solving } \\
\text { problems" This formulation however does } \\
\text { not explicitly enough state that the main } \\
\text { purpose of algebraic manipulation is to } \\
\text { create equivalent expressions which are } \\
\text { more suitable for a specific task. Neither do } \\
\text { the Assessment Standards refer to this } \\
\text { fundamental principle. } \\
\text { Verdict: Algebraic manipulation as a } \\
\text { means of constructing more convenient } \\
\text { equivalent expressions is inadequately } \\
\text { addressed. }\end{array}$} \\
\hline & & & & 4B & 9 & \\
\hline & & \multicolumn{5}{|c|}{ Final verdict: 1.1 .2 is very inadequately addressed in LO2. } \\
\hline
\end{tabular}

Table 4. Aspect 1 (cont.): enable learners to experience and appreciate algebra as generalised arithmetic (LO2).

\section{Table 4 Assessment Standards}

4A: Uses conventions of algebraic notation and the commutative, associative and distributive laws to:

- collect like terms

- multiply or divide an algebraic expression

- simplify algebraic expressions given in bracket notation

4B: Uses the distributive law and manipulative skills developed in grade 8 to:

- find the product of two binomials

- factorise algebraic expressions 


\begin{tabular}{|c|c|c|c|c|c|c|}
\hline & \multicolumn{5}{|c|}{ Where/how addressed in curriculum } & \multirow[t]{2}{*}{ Comments and verdict regarding 1.1 .3} \\
\hline \multirow[t]{7}{*}{1.1 .3} & LO & Phase(s) & $\begin{array}{l}\text { Numbered } \\
\text { statements }\end{array}$ & $\begin{array}{l}\text { Assessment } \\
\text { Standard }\end{array}$ & Grade(s) & \\
\hline & \multirow[t]{6}{*}{1} & $F, I, S$ & $\begin{array}{l}1 \\
2\end{array}$ & & $\begin{array}{l}\text { All } \\
\text { grades in } \\
\text { GET }\end{array}$ & $\begin{array}{l}\text { Comment: Statements }{ }^{I} \text { and }{ }^{2} \text { from the LO } \\
\text { Focus are of a general nature, and are } \\
\text { addressed in more detail in the rest of this } \\
\text { table. }\end{array}$ \\
\hline & & $\mathrm{F}$ & & & & $\begin{array}{l}\text { Comment: This aspect needs not be } \\
\text { addressed at the Foundation Phase level. } \\
\text { However, where the opportunity arises, } \\
\text { teachers should introduce it informally }\end{array}$ \\
\hline & & $\mathrm{I}$ & 5 & $5 \mathrm{~A}$ & $4 ; 5 ; 6$ & Comment: It is important that learners \\
\hline & & & 6 & 5B & 6 & $\begin{array}{l}\text { develop an explicit knowledge and } \\
\text { understanding of the structural aspects of } \\
\text { the properties of operations, in order to } \\
\text { transfer these to manipulation in algebra. } \\
\text { Without this explicit knowledge and } \\
\text { understanding, learners will not be able to } \\
\text { see the structural similarities between } \\
\text { calculation in arithmetic and manipulation in } \\
\text { algebra. } \\
\text { Verdict: Addressed, but very implicitly. Not } \\
\text { indicating to teachers the importance of } \\
\text { explicit knowledge of the structural aspects } \\
\text { of properties of operations. }\end{array}$ \\
\hline & & S & 7 & $5 \mathrm{C}$ & $7 ; 8$ & $\begin{array}{l}\text { Verdict: Addressed, but very implicitly. Not } \\
\text { indicating to teachers the importance of } \\
\text { explicit knowledge of the structural aspects } \\
\text { of properties of operations. }\end{array}$ \\
\hline & & \multicolumn{5}{|c|}{$\begin{array}{l}\text { Final verdict: } 1.1 .3 \text { is very implicitly addressed in LO1. Teachers need to be aware of the } \\
\text { importance of explicit knowledge and understanding of the structural aspects of properties of } \\
\text { operations. }\end{array}$} \\
\hline
\end{tabular}

Table 5. Aspect 1 (cont.): enable learners to experience and appreciate algebra as generalised arithmetic (LO1).

5A:

\section{Table 5 Assessment Standards}

- Calculates by selecting and using operations appropriate to solving problems that involve:

- addition and subtraction of whole numbers

- multiplication of at least $2 / 3 / 4$ digit by $2 / 3$ digit numbers

- division of at least whole $2 / 3 / 4$ digit numbers by $2 / 3$ digit numbers

- Uses a range of techniques to perform calculations, including building up and breaking down numbers

- Recognises, describes and uses the commutative, associative and distributive properties (the expectation is that learners should be able to use these properties and not necessarily know the names of the properties)
5B: Multiple operations on whole numbers with or without brackets

5C:

- Uses a range of techniques to perform calculations, including the commutative, associative and distributive properties

- Recognises, describes and uses the commutative, associative and distributive properties (the expectation is that learners should be able to use these properties and not necessarily know the names of the properties) 


\begin{tabular}{|c|c|c|c|c|c|c|}
\hline & \multicolumn{5}{|c|}{ Where/how addressed in curriculum } & \multirow[t]{2}{*}{ Comments and verdict regarding 1.1.2 } \\
\hline \multirow[t]{5}{*}{1.1 .3} & LO & Phase(s) & $\begin{array}{l}\text { Numbered } \\
\text { statements }\end{array}$ & $\begin{array}{c}\text { Assessment } \\
\text { Standard }\end{array}$ & Grade(s) & \\
\hline & 2 & $F, I, S$ & 10 & & $\begin{array}{c}\text { All } \\
\text { grades in } \\
\text { GET }\end{array}$ & \\
\hline & & \multirow[t]{2}{*}{$\mathrm{S}$} & \multirow{2}{*}{$\begin{array}{l}24 \\
25 \\
26\end{array}$} & $6 \mathrm{~A}$ & 8 & \multirow{3}{*}{$\begin{array}{l}\text { Comment: The Phase Focus merely } \\
\text { mentions "study properties of algebraic } \\
\text { expressions", but it does not in any way } \\
\text { indicate the fundamental structural } \\
\text { similarities and differences between } \\
\text { arithmetic (numerical) expressions and } \\
\text { algebraic expressions. } \\
\text { Verdict: Structural similarities are } \\
\text { inadequately addressed. Teachers need to } \\
\text { know these similarities and differences. }\end{array}$} \\
\hline & & & & $6 \mathrm{~B}$ & 9 & \\
\hline & & & & & $d r e$ & \\
\hline
\end{tabular}

Table 6. Aspect 1 (cont.): enable learners to experience and appreciate algebra as generalised arithmetic (LO2).

\begin{tabular}{|c|c|c|c|c|c|c|}
\hline & \multicolumn{5}{|c|}{ Where/how addressed in curriculum } & \multirow[t]{2}{*}{ Comments and verdict regarding $\mathbf{1 . 2}$} \\
\hline \multirow[t]{5}{*}{1.2} & LO & Phase(s) & $\begin{array}{l}\text { Numbered } \\
\text { statements }\end{array}$ & $\begin{array}{l}\text { Assessment } \\
\text { Standard }\end{array}$ & Grade(s) & \\
\hline & \multirow[t]{4}{*}{1} & $F$ & & & & \multirow{2}{*}{$\begin{array}{l}\text { Comment: It is not expected for } 1.2 \text { to be } \\
\text { addressed in Foundation or Intermediate } \\
\text { Phases. }\end{array}$} \\
\hline & & 1 & & & & \\
\hline & & S & 7 & $7 \mathrm{~A}$ & $7 ; 8$ & $\begin{array}{l}\text { Comment: Repeated recognition, descrip- } \\
\text { tion and use of the properties of operations } \\
\text { should (with teacher guidance) enable } \\
\text { learners to be explicitly aware of them. The } \\
\text { (intuitive) need to describe them in a } \\
\text { generalised way (words and later symbols) } \\
\text { should arise in the Senior Phase. }\end{array}$ \\
\hline & & \multicolumn{5}{|c|}{$\begin{array}{l}\text { Final verdict: } 1.2 \text { is hardly addressed in LO } 1 \text {. One would however not expect it here, but } \\
\text { rather in LO2. }\end{array}$} \\
\hline
\end{tabular}

Table 7. Aspect 1 (cont.): enable learners to experience and appreciate algebra as generalised arithmetic (LO1).

\section{Table 6 Assessment Standards}

6A: Uses conventions of algebraic notation and the commutative, associative and distributive laws to:

- collect like terms

- multiply or divide an algebraic expression

- simplify algebraic expressions given in bracket notation

6B: Uses the distributive law and manipulative skills developed in grade 8 to:
- find the product of two binomials

- factorise algebraic expressions

\section{Table 7 Assessment Standards}

7A: Recognises, describes and uses the commutative, associative and distributive properties (the expectation is that learners should be able to use these properties and not necessarily know the names of the properties) 
Does Curriculum 2005 promote successful learning of elementary algebra?

\begin{tabular}{|c|c|c|c|c|c|c|}
\hline & \multicolumn{5}{|c|}{ Where/how addressed in curriculum } & \multirow[t]{2}{*}{ Comments and verdict regarding 1.2} \\
\hline \multirow[t]{5}{*}{1.2} & LO & Phase(s) & $\begin{array}{l}\text { Numbered } \\
\text { statements }\end{array}$ & $\begin{array}{l}\text { Assessment } \\
\text { Standard }\end{array}$ & Grade(s) & \\
\hline & \multirow[t]{4}{*}{2} & $\mathrm{~F}$ & & & & $\begin{array}{l}\text { Comment: It is not expected for } 1.2 \text { to be } \\
\text { addressed in Foundation Phase. }\end{array}$ \\
\hline & & 1 & 16 & $8 \mathrm{~A}$ & $4-6$ & \\
\hline & & S & $\begin{array}{l}20 \\
24\end{array}$ & $8 \mathrm{~B}$ & $\begin{array}{l}7 \\
8\end{array}$ & $\begin{array}{l}\text { Comment: Describing rules governing } \\
\text { patterns using symbols should develop } \\
\text { understanding of these symbols as } \\
\text { variables and place holders for numbers. It } \\
\text { should also develop understanding of } \\
\text { algebraic expressions and equations as a } \\
\text { shorthand way of expressing calculating } \\
\text { procedures and relationships, namely, as a } \\
\text { language. } \\
\text { The concept of equivalence is fundamental } \\
\text { to understanding and appreciating } \\
\text { manipulation in algebra, and therefore the } \\
\text { semantics and syntax of algebra as a } \\
\text { language. }\end{array}$ \\
\hline & & \multicolumn{5}{|c|}{ Verdict: 1.2 is adequately addressed in LO 2.} \\
\hline
\end{tabular}

Table 8. Aspect 1 (cont.): enable learners to experience and appreciate algebra as generalised arithmetic (LO2).

\begin{tabular}{|c|c|c|c|c|c|c|}
\hline & \multicolumn{5}{|c|}{ Where/how addressed in curriculum } & \multirow{2}{*}{$\begin{array}{l}\text { Comments and verdict regarding } 2.1- \\
2.4\end{array}$} \\
\hline \multirow{5}{*}{$\begin{array}{l}2.1 \\
2.2 \\
2.3 \\
2.4\end{array}$} & LO & Phase(s) & $\begin{array}{l}\text { Numbered } \\
\text { statements }\end{array}$ & $\begin{array}{c}\text { Assessment } \\
\text { Standard }\end{array}$ & Grade(s) & \\
\hline & \multirow[t]{4}{*}{1} & $\mathrm{~F}$ & $\begin{array}{l}3 \\
1\end{array}$ & $9 \mathrm{~A}$ & $1 ; 2 ; 3$ & \multirow{3}{*}{$\begin{array}{l}\text { Comment: The notion that the number of } \\
\text { skips corresponds to a final answer, and } \\
\text { that one could determine the final answer } \\
\text { by using the number of skips, form the } \\
\text { embryonic beginnings of the concept of } \\
\text { variable, and of a relationship between } \\
\text { variables. } \\
\text { Verdict: Skip counting is implicitly } \\
\text { addressed in } 2.1 \text { and } 2.2 \text {. } \\
\text { Comment: Ratio, and rate and proportion } \\
\text { in particular, are important components of } \\
\text { the function concept, thereby including the } \\
\text { concept of variable. In Grade } 9 \text {, proportion } \\
\text { problems should be solved within a } \\
\text { function context, using formulae ( } \mathrm{y}=\mathrm{kx} \\
\text { and } x y=\mathrm{k} \text { ) and graphs. } \\
\text { Verdict: Ratio, rate and proportion are } \\
\text { adequately addressed in } 2.1 \text { to } 2.4\end{array}$} \\
\hline & & $I$ & $\begin{array}{l}3 \\
1\end{array}$ & 9B & $4 ; 5 ; 6$ & \\
\hline & & $S$ & \begin{tabular}{|l|}
3 \\
1 \\
7
\end{tabular} & $9 \mathrm{C}$ & $7 ; 8 ; 9$ & \\
\hline & & \multicolumn{5}{|c|}{$\begin{array}{l}\text { Final verdict: } 2.1-2.4 \text { are addressed implicitly in LO1. Teachers need to be aware of the } \\
\text { potential the indicated Assessment Standards have to develop the concept of variable, and } \\
\text { utilize these in an ever-increasing generalised form, describing patterns and relationships in } \\
\text { words, and eventually in the Senior Phase using flow diagrams, formulae and graphs. }\end{array}$} \\
\hline
\end{tabular}

Table 9. Aspect 2: enable learners to use and appreciate algebra as a means to describe relationships between quantities that vary (namely, variables) inside and outside mathematics (LO1). 
8A:

Table 8 Assessment Standards

- Investigates and extends numeric and geometric patterns

- Writes number sentences to describe a problem situation

- Solves or completes number sentences

8B:

- Investigates and extends numeric and geometric patterns

- Describes, explains and justifies observed relationships or rules in algebra

- Solves number sentences/equations

- Uses conventions of algebraic notation and the commutative, associative and distributive laws to

- compare different representations of algebraic expressions involving one or more operations, selecting those which are equivalent

- write algebraic expressions, formulae or equations in simpler or more useful equivalent forms in context

\section{Table 9 Assessment Standards}

9A: Counts forwards and backwards in ones, tens, 9B: fives, twos, etc

- counts forwards and backwards in a variety of intervals

- solves problems that involve ratio and rate

9C:

- counts forwards and backwards in a variety of intervals

- solves problems that involve ratio and rate (and proportion in grade 9)

\section{Table 10 Assessment Standards}

10A:

- Copies and extends simple patterns using physical objects and drawings

- Copies and extends simple number sequences

- Creates own patterns

- Describes observed patterns

- Identifies, describes and copies geometric patterns in natural and cultural artefacts

10B:

- Investigates and extends numeric and geometric patterns looking for relationship or rule

- Describes observed relationships or rules in own words

- Determines output values for given input values using

- verbal descriptions,
- flow diagrams

- tables (grade 6)

- Writes number sentences to describe a problem situation.

- Solves or completes number sentences by inspection or trial-and-improvement

- Determine the equivalence of different descriptions of the same relationship or rule presented

- verbally,

- in flow diagram

- by number sentences (grade 6 )

- in tables (grade 6)

10C:

- Investigates and extends numeric and geometric patterns looking for a relationship or rule

- Describes, explains and justifies observed relationships in own words (or algebra - grade 8)

- Represents and uses relationships between variables in order to determine input and output values in a variety of ways using:

- verbal descriptions

- flow diagrams

- tables

- formulae and equations (grade 8 and 9)

- Solves or completes number sentences (grade 7)

- Solves equations by inspection, trial-andimprovement or algebraic processes (grade 8 and 9)

- Describes a situation by interpreting a graph of the situation, or draws a graph from the description of a situation (grade 7 and 8)

- Draws graphs on the Cartesian plane for given equations, or determine equations from given graphs (grade 9)

- Determines, analyses and interprets the equivalence of different descriptions of the same relationship or rule (verbal, flow diagrams, tables, equations/expressions, graphs) 
Does Curriculum 2005 promote successful learning of elementary algebra?

\begin{tabular}{|c|c|c|c|c|c|c|}
\hline & \multicolumn{5}{|c|}{ Where/how addressed in curriculum } & \multirow{2}{*}{$\begin{array}{l}\text { Comments and verdict regarding } 2.1- \\
\qquad 2.4\end{array}$} \\
\hline \multirow{6}{*}{$\begin{array}{l}2.1 \\
2.2 \\
2.3 \\
2.4\end{array}$} & LO & Phase(s) & $\begin{array}{l}\text { Numbered } \\
\text { statements }\end{array}$ & $\begin{array}{l}\text { Assessment } \\
\text { Standard }\end{array}$ & Grade(s) & \\
\hline & \multirow[t]{5}{*}{2} & $F, I, S$ & $\begin{array}{l}8 \\
10\end{array}$ & & $1-9$ & $\begin{array}{l}\text { Comment: The LO Focus explicitly states } \\
\text { recognising and describing patterns and } \\
\text { relationships from an early age, with } \\
\text { increasing levels of sophistication (and } \\
\text { thus generalisation and formalisation). }\end{array}$ \\
\hline & & $\mathrm{F}$ & $\begin{array}{l}12 \\
13 \\
14\end{array}$ & $10 \mathrm{~A}$ & $1 ; 2 ; 3$ & \multirow{3}{*}{$\begin{array}{l}\text { Comment: In the Foundation Phase the } \\
\text { emphasis is on the recognition and } \\
\text { extension of patterns, while in the } \\
\text { Intermediate phase the focus shifts } \\
\text { towards recognising the relationship } \\
\text { between the place of a number in a } \\
\text { sequence and its value (therefore viewing } \\
\text { position and value as the two variables). } \\
\text { In the Senior Phase these relationships } \\
\text { are formally described using algebraic } \\
\text { language (formulas / equations) and } \\
\text { graphs. } \\
2.4 \text { is partially addressed by the } \\
\text { Assessment Standard "...uses relation- } \\
\text { ships between variables in order to } \\
\text { determine input and output values ... } \\
\text { using formulae and equations (grade } 8 \\
\text { and 9)". However, it is not explicitly stated } \\
\text { that substitution into formulas/algebraic } \\
\text { expressions to find output values, and } \\
\text { solving equations to determine input } \\
\text { values are two inverse processes. Still, } \\
\text { the curriculum provides a solid context } \\
\text { within which to introduce solving algebraic } \\
\text { equations, namely as a means to find } \\
\text { values of the input variable. }\end{array}$} \\
\hline & & I & $\begin{array}{l}15 \\
16 \\
17\end{array}$ & 10B & $4 ; 5 ; 66$ & \\
\hline & & $\mathrm{S}$ & $\begin{array}{l}18 \\
19 \\
20 \\
21 \\
22 \\
23\end{array}$ & $10 \mathrm{C}$ & $7 ; 8 ; 9$ & \\
\hline & & \multicolumn{5}{|c|}{$\begin{array}{l}\text { Final verdict: } 2.1-2.4 \text { are thoroughly addressed in LO2. To a large extent } 2.1-2.4 \text { form the } \\
\text { core of (elementary) algebra, developing within the context of patterns and relationships the } \\
\text { rationale for algebraic notation such as letter symbols, algebraic expressions and equations, } \\
\text { and their manipulation. }\end{array}$} \\
\hline
\end{tabular}

Table 10. Aspect 2: enable learners to use and appreciate algebra as a means to describe relationships between quantities (LO2).

\section{Table 11 Assessment Standards}

11A: Building up and breaking down number

11B: Estimates and calculates by selecting and using operations appropriate to solving problems that involve addition, subtraction, multiplication, division, equal sharing with remainders, ...
11C:

- Solve problems in context

- Solves problems that involve ratio and rate (and in grade 9, also proportion)

- Estimates and calculates by selecting and using operations appropriate to solving problems 


\begin{tabular}{|c|c|c|c|c|c|c|}
\hline & \multicolumn{5}{|c|}{ Where/how addressed in curriculum } & \multirow[t]{2}{*}{ Comments and verdict regarding 3} \\
\hline \multirow{4}{*}{ - } & LO & Phase(s) & $\begin{array}{l}\text { Numbered } \\
\text { statements }\end{array}$ & $\begin{array}{c}\text { Assessment } \\
\text { Standard }\end{array}$ & Grade(s) & \\
\hline & \multirow[t]{3}{*}{1} & $\mathrm{~F}$ & 4 & $11 \mathrm{~A}$ & $1 ; 2 ; 3$ & $\begin{array}{l}\text { Comment: Young learners often intuitively } \\
\text { calculate by breaking down numbers, a } \\
\text { result of them modelling the (physical) } \\
\text { problem they try to solve. } \\
\text { Verdict: Although very far removed from } \\
\text { algebra, the notion of modelling a problem } \\
\text { using mathematics is formed, and should } \\
\text { be encouraged, in this Phase. }\end{array}$ \\
\hline & & I & 6 & 11B & $4 ; 5 ; 6$ & $\begin{array}{l}\text { Comment: Solving problems implies } \\
\text { modelling real-life situations, using } \\
\text { mathematics to solve them. } \\
\text { Verdict: Although very far removed from } \\
\text { algebra, the notion of modelling a problem } \\
\text { using mathematics is formed, and should } \\
\text { be encouraged, in this Phase. }\end{array}$ \\
\hline & & S & 7 & $11 \mathrm{C}$ & $7 ; 8 ; 9$ & $\begin{array}{l}\text { Comment: Solving problems imply } \\
\text { modelling real-life situations, using } \\
\text { mathematics to solve them. } \\
\text { Verdict: Although LO1 does not refer to } \\
\text { algebra as such, familiarity with problem } \\
\text { solving, and therefore modelling, in a } \\
\text { number context should pave the way for } \\
\text { problem solving, and modelling, in a } \\
\text { algebra context. }\end{array}$ \\
\hline
\end{tabular}

Table 11. Aspect 3: enable learners to use and appreciate algebra as a tool to solve problems inside and outside mathematics, often through a modelling process (LO1).

\begin{tabular}{|c|c|c|c|c|c|c|}
\hline & \multicolumn{5}{|c|}{ Where/how addressed in curriculum } & \multirow[t]{2}{*}{ Comments and verdict regarding 3} \\
\hline \multirow{3}{*}{ - } & LO & Phase(s) & $\begin{array}{l}\text { Numbered } \\
\text { statements }\end{array}$ & $\begin{array}{c}\text { Assessment } \\
\text { Standard }\end{array}$ & Grade(s) & \\
\hline & \multirow[t]{2}{*}{2} & $\mathrm{~F}, \mathrm{I}, \mathrm{S}$ & $\begin{array}{l}8 \\
9\end{array}$ & & & $\begin{array}{l}\text { Verdict: The LO2 Focus explicitly refers to } \\
\text { solving problems within a patterns and } \\
\text { relationship context. This implicitly refers to } \\
\text { formulas/equations as a tool to solve } \\
\text { problems. Unfortunately, the latter aspect } \\
\text { is not stated clearly enough. }\end{array}$ \\
\hline & & S & $\begin{array}{l}19 \\
20 \\
21 \\
22 \\
23 \\
24 \\
25 \\
26\end{array}$ & $12 \mathrm{~A}$ & $7 ; 8 ; 9$ & $\begin{array}{l}\text { Comment: The intention of the curriculum } \\
\text { reflects the need for learners to use and } \\
\text { appreciate algebra as a tool to solve } \\
\text { problems inside and outside mathematics, } \\
\text { often through the modelling process. } \\
\text { Verdict: } 3 \text { is adequately, however quite } \\
\text { implicitly, addressed. }\end{array}$ \\
\hline
\end{tabular}

Table 12. Aspect 3: enable learners to use and appreciate algebra as a tool to solve problems inside and outside mathematics (LO2). 
12A:

\section{Table 12 Assessment Standards}

- Investigates and extends numeric and geometric patterns looking for a relationship or rule

- Describes, explains and justifies observed relationships in own words (or algebra - grade 8)

- Represents and uses relationships between variables in order to determine input and output values in a variety of ways using:

- verbal descriptions

- flow diagrams

- tables

- formulae and equations (grade 8 and 9)

- Solves or completes number sentences (grade 7)

- Solves equations by inspection, trial-andimprovement or algebraic processes (grade 8 and 9)

- Describes a situation by interpreting a graph of the situation, or draws a graph from the description of a situation (grade 7 and 8 )

- Draws graphs on the Cartesian plane for given equations, or determine equations from given graphs (grade 9)

- Determines, analyses and interprets the equivalence of different descriptions of the same relationship or rule (verbal, flow diagrams, tables, equations/expressions, graphs).

\section{Conclusion}

It appears that the RNCS (Mathematics) to a fair extent succeeds in addressing current concerns and recommendations regarding the teaching and learning of (elementary) algebra, thereby fairly well aligning it with international curricula, notably that of the USA. Particularly meritorious is the curriculum's development of the notion of variables/-ility, relationships between variables, and the emphasis on increasing levels of sophistication to describe these relationships, culminating in symbolic algebraic notation (letter symbols, algebraic expressions and equations) and graphs. The curriculum designers should be congratulated with this attempt.

There are however concerns and recommendations that are not explicitly addressed, as indicated in Tables 1 to 12 under "verdict". These may have been omitted either deliberately to prevent an overload of information in the curriculum document, or by mistake. Whatever the case may be, teachers and teacher educators need to get the full picture, and therefore these omissions need to be addressed - either through additional documentation, or through training.

Another major concern is that in spite of a fairly complete curriculum statement regarding algebra, the question remains whether mathematics teachers and teacher educators are aware of the expectations and implications of this curriculum. Do they read into the curriculum that algebra is not only a high school topic, but that its roots lie in and must be developed right from the Foundation Phase, through the Intermediate and Senior Phases, with increasing levels of generalisation and symbolisation?

\section{Recommendations}

Based on what has been described so far, the following recommendations are made:

- Inset and preset programmes must address General Education and Training (GET) teachers' and student teachers' beliefs about mathematics and the learning of algebra (and mathematics in general), and guide them towards a clear understanding of the nature of algebra and the learning of algebra, as intended by the curriculum.

- Learning programmes need to be designed to assist teachers to implement the intended algebra curriculum throughout the GET phase.

Research needs to be conducted to inform and support these learning programmes, in particular regarding learners' abilities to cope with the curriculum's expectations and teachers' abilities to implement such learning programmes. Extensive research is currently being undertaken in the USA, where there is a strong drive to "algebraise" the "arithmetic curriculum" (Rivera, 2006). While mathematics educators and researchers in the USA "welcome the integration of algebra into the early mathematics curriculum", they state that "these ... do not diminish the need for research; quite the contrary, they highlight the need for a solid research base for guiding the mathematics education community along this new venture" (Carraher, Schliemann, Brizuela \& Earnest, 2006). In South Africa, this research field is still largely untouched.

\section{References}

Bednarz, N., Kieran, C. \& Lee, L. (Eds.). (1996). Approaches to Algebra: Perspectives for Research and Teaching. Dordrecht: Kluwer Academic Publishers.

Booth, L.R. (1986). Difficulties in Algebra. The Australian Mathematics Teacher, 42(3), 2-4. 
Booth, L.R. (1988). Children's Difficulties in Beginning Algebra. In A.F. Coxford (Ed.), The Ideas of Algebra, K-12 (pp 20-32). Reston, NCTM.

Booth, L.R. (1989). A question of structure. In S. Wagner \& C. Kieran (Eds.), Research Issues in the Learning and Teaching of Algebra (pp 5759). Reston: NCTM.

Carraher, D.W., Schliemann, A.D., Brizuela, B.M. \& and Earnest, D. (2006). Arithmetic and Algebra in early Mathematics Education. Journal for Research in Mathematics Education, 37(2), 87-115.

Department of Education. (2002). Revised National Curriculum Statement Grades $R-9$ (Schools) Policy. Pretoria: Government Printer.

Herscovics, N. (1989). Cognitive Obstacles encountered in the Learning of Algebra. In S. Wagner. \& C. Kieran (Eds.). Research Issues in the Learning and Teaching of Algebra (pp 6086). Reston: NCTM.

Kaput, J. (1999). Teaching and Learning a New Algebra. In E. Fennema \& T. Romberg (Eds.). Mathematics Classrooms that Promote Understanding (pp 133-156). London: Lawrence Erlbaum.

Kieran, C. (1989). The early learning of algebra: A structural perspective. In $\mathrm{S}$. Wagner \& $\mathrm{C}$. Kieran (Eds.). Research Issues in the Learning and Teaching of Algebra (pp 33-56). Reston: NCTM.

Kinzel, M.T. (1999). Understanding Algebraic Notation from the Students' Perspective. The Mathematics Teacher, 92(5), 436-442.

Küchemann, D. (1981) Algebra. In K.M. Hart (Ed.), Children's Understanding of Mathematics (pp 102-110). London: John Murray.
Matz, M. (1979). Towards a process model for high school algebra errors. (Working Paper No. 181). Cambridge: Massachusetts Institute of Technology.

National Council of Teachers of Mathematics. (1994). A Framework for Constructing a Vision of Algebra. Prepared by the Algebra Working Group of the Council of Teachers of Mathematics. Reston, VA: NCTM.

National Council of Teachers of Mathematics. (2000). Principles and Standards for School Mathematics. Reston, VA: NCTM.

Orton, A. \& Frobisher, L. (1996). Insights into teaching Mathematics. London: Cassell.

Rivera, F.D. (2006). Changing the Face of Arithmetic: Teaching Children Algebra. Teaching Children Mathematics, 2(16), 206311.

Sfard, A. (1991). On the dual nature of mathematical conceptions: reflections on process and object as different sides of the same coin. Educational Studies in Mathematics, 22, $1-36$.

Vergnaud, G. (1989). Multiplicative Structures. In J. Hiebert \& M. Behr (Eds.). Number concepts and Operations in the Middle Grades (pp 141161). Reston, Virginia: NCTM.

Vermeulen, C.F. (1995). Verhoging van laerskoolleerlinge se vlak van bewustheid van die distributiewe eienskap in rekenkunde [Increasing primary school learners' level of awareness of the distributive property in arithmetic]. Unpublished D Ed thesis, University of Stellenbosch.

Vermeulen, N. (2000). Student teachers' concept images of algebraic expressions. In T. Nakahara \& K. Koyama (Eds.). Proceedings of the $24^{\text {th }}$ Conference of the International Group for the Psychology of Mathematics Education, Volume 4 (pp 257-264). Hiroshima: Nishiki.

"Algebra reverses the relative importance of the factors in ordinary language. It is essentially a written language, and it endeavours to exemplify in its written structures the patterns which it is its purpose to convey. The pattern of the marks on paper is a particular instance of the pattern to be conveyed to thought. The algebraic method is our best approach to the expression of necessity, by reason of its reduction of accident to the ghostlike character of the real variable." 